\title{
Language Perception and Inhibitors through the Brain Chemical Neurotransmitters
}

Fatemeh Mollaamin*

Department of French Language and Literature, Iran

*Corresponding author: Fatemeh Mollaamin, Department of French Language and Literature, Iran

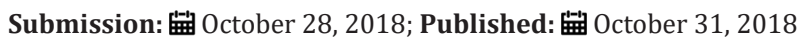

\section{Opinion}

Transferring the chemical messaging in the brain permits daily functions such as thinking, learning, movements, speaking, listening and other activities due to communicating the brain with itself which sends out the chemical information from one neuron or nerve cell to another. Neurotransmitters in the brain are effective in language processing which provide an account of language development that conducts human speech mechanism.

It has been attempted to discover the inhibitors of language development due to blocking of dopamine (DA) by cocaine (CA) when brain cannot control the functions of learning and reward. So, it has been investigated the decrease of DA effectiveness in the brain using modeling the structures of DA, CA, DA-CA, $\mathrm{TiO}_{2}$ nano-surface, and $\mathrm{DA}-\mathrm{CA}-\mathrm{TiO}_{2}$ nano-cluster due to discovering the presence of cocaine (CA) as a stopper of DA release in brain (Figure 1). It has been also investigated Dopamine-cocaine (DA-CA) dissociating by its $\mathrm{OH}$ bonds and adsorbing on $\mathrm{TiO}_{2}$ nano-surface as the bidentate mode that DA-CA places perpendicular to the surface of $\mathrm{TiO}_{2}$ (Figure 2).

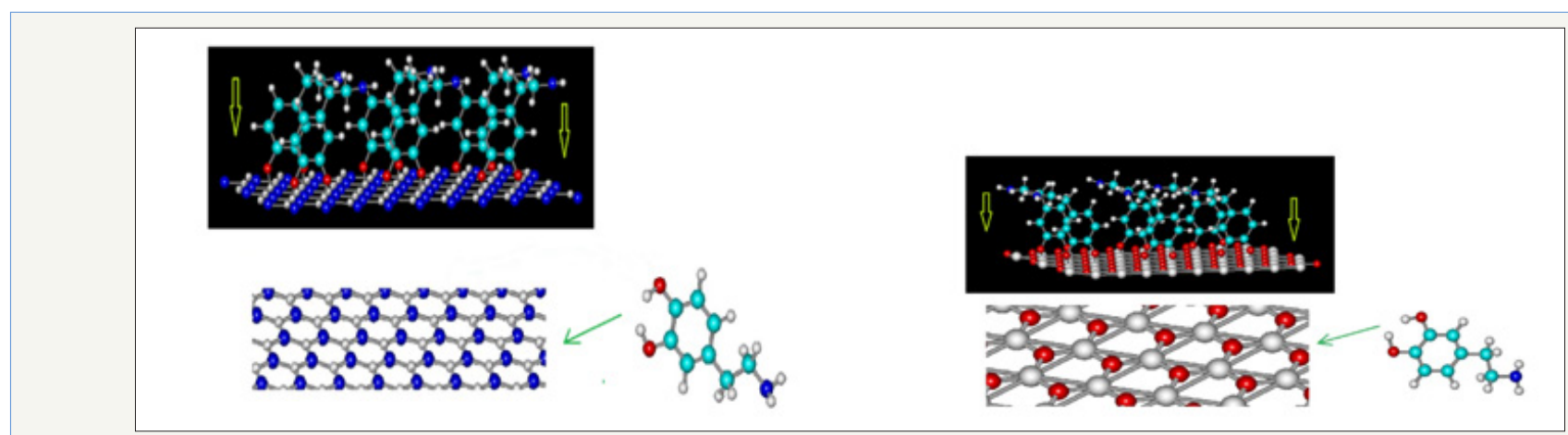

Figure 1: The chemical adsorption of dopamine a) on the Boron Nitride nanostructure and b) $\mathrm{TiO}_{2}$ surface.

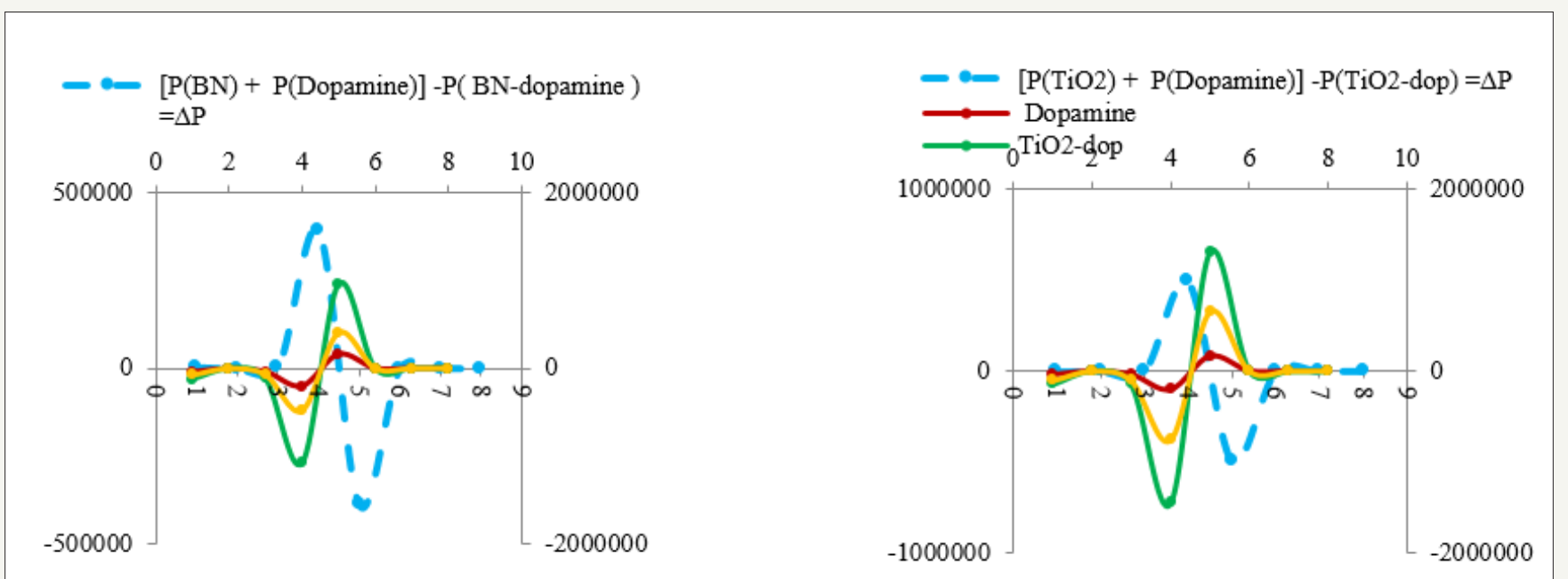

Figure 2: Simulated thermodynamic parameters of a)Dopamine-BN surface and b)Dopamine- $\mathrm{TiO}_{2}$ surface. 


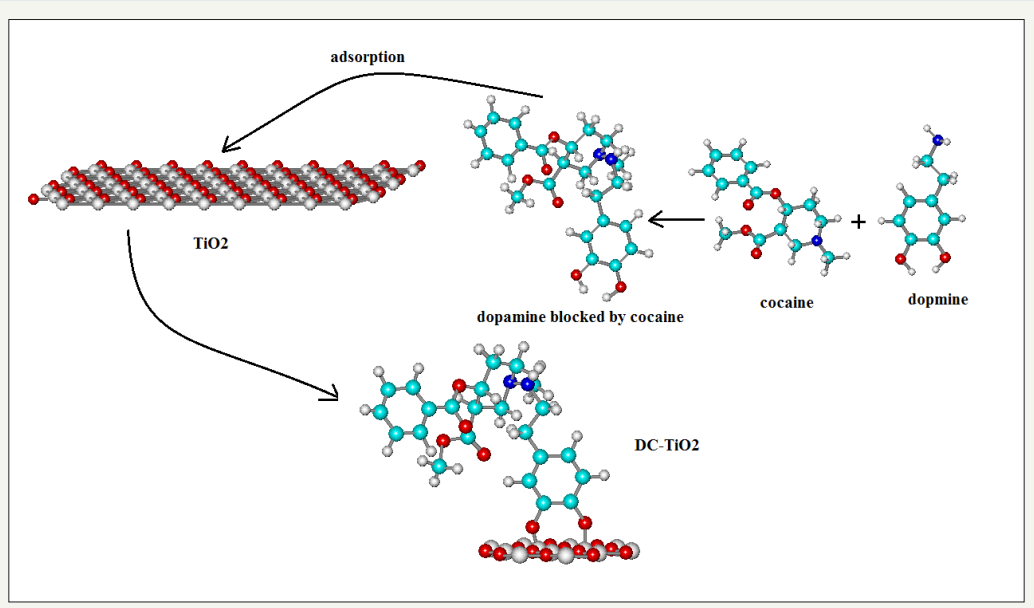

Figure 3: The path of cocaine functions through the blocked dopamine in the brain.

During brain is fulfilled unexpectedly, dopamine releases largely, making the Limbic pleasure center to take note for remembering how to copy the positive experience. In contrast, negative thoughts reduce dopamine as a signal to avoid repeating them which is a key learning mechanism dealing with memory-formation and motivation because researchers believe that brain proves a new temporary neural network to process a new development (Figure $3)$.

So, it has been indicated that after blocking of dopamine by cocaine inhibitor, brain cannot play its role for releasing neurotransmitters which have the responsibility of learning a new language and enjoying in daily life.

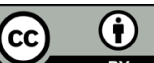

Creative Commons Attribution 4.0 International License

For possible submissions Click Here

\section{Submit Article}

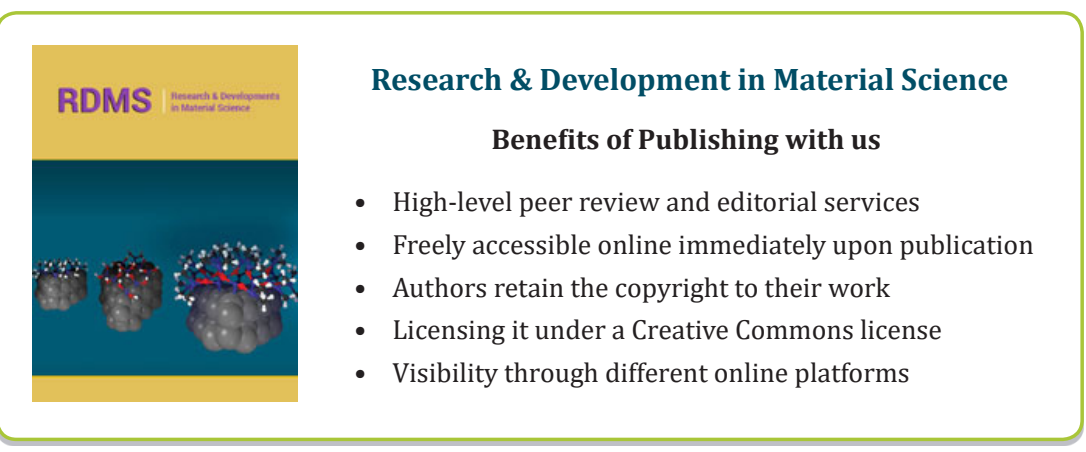

